ARTICLE

\title{
Ambient methane functionalization initiated by electrochemical oxidation of a vanadium (V)-oxo dimer
}

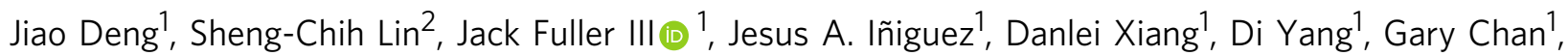
Hao Ming Chen (10 ${ }^{2 凶}$, Anastassia N. Alexandrova (i] ${ }^{1,3 凶} \&$ Chong Liu (D) ${ }^{1 凶}$

The abundant yet widely distributed methane resources require efficient conversion of methane into liquid chemicals, whereas an ambient selective process with minimal infrastructure support remains to be demonstrated. Here we report selective electrochemical oxidation of $\mathrm{CH}_{4}$ to methyl bisulfate $\left(\mathrm{CH}_{3} \mathrm{OSO}_{3} \mathrm{H}\right)$ at ambient pressure and room temperature with a molecular catalyst of vanadium $(\mathrm{V})$-oxo dimer. This water-tolerant, earthabundant catalyst possesses a low activation energy $\left(10.8 \mathrm{kcal} \mathrm{mol}^{-1}\right)$ and a high turnover frequency (483 and $1336 \mathrm{hr}^{-1}$ at 1-bar and 3-bar pure $\mathrm{CH}_{4}$, respectively). The catalytic system electrochemically converts natural gas mixture into liquid products under ambient conditions over $240 \mathrm{~h}$ with a Faradaic efficiency of $90 \%$ and turnover numbers exceeding 100,000 . This tentatively proposed mechanism is applicable to other $d^{0}$ early transition metal species and represents a new scalable approach that helps mitigate the flaring or direct emission of natural gas at remote locations.

\footnotetext{
${ }^{1}$ Department of Chemistry and Biochemistry, University of California, Los Angeles, Los Angeles, CA 90095, USA. ${ }^{2}$ Department of Chemistry, National Taiwan University, Taipei 10617, Taiwan. ${ }^{3}$ California NanoSystems Institute, Los Angeles, CA 90095, USA. ${ }^{凶}$ email: haomingchen@ntu.edu.tw; ana@chem.ucla.edu; chongliu@chem.ucla.edu
} 
T he wide geological distribution of natural gas resources leads to an undesirable loss of methane $\left(\mathrm{CH}_{4}\right)$ especially at remote locations via flaring or direct emission into the atmosphere ${ }^{1,2}$. One possible strategy to mitigate such an issue is to convert $\mathrm{CH}_{4}$ into liquid chemicals at the source of emission under ambient condition with minimal reliance on an industrial infrastructure ${ }^{2}$. Fundamentally, this catalytic conversion requires low activation energy and high reactivity, in order to accommodate the low thermal energy and partial pressure of $\mathrm{CH}_{4}$ substrate at ambient condition. Existing approaches of $\mathrm{CH}_{4}$ functionalization usually operated at high pressure and/or elevated temperature ${ }^{3-16}$, involve metal-catalyzed reactions $s^{3-7}$, superacid-based activation ${ }^{17}$, or catalysis based on peroxo species for a free-radical chain mechanism ${ }^{8-10}$. For the metal-catalyzed reactions reported by Periana and others (Fig. 1a ${ }^{3-6}$, electrophilic activation of $\mathrm{CH}_{4}$ is followed by an oxidation process that regenerates the metal active sites, mostly precious metals including Pt and Pd. Yet, in ambient conditions, the reactivities of these electrophilic metal species seem insufficient to activate $\mathrm{CH}_{4}$. In the approaches based on radical chain mechanism (Fig. 1b) ${ }^{8-10}$, initiators including peroxo species yield oxygen radicals that activate $\mathrm{CH}_{4}$ at room temperature with low activation energies ${ }^{18}$. But it is uneasy to achieve a sustained, selective catalytic process that generates and replenishes radical species. The challenge of balancing the reactivity and regeneration of active species call for an alternative approach for ambient $\mathrm{CH}_{4}$ functionalization.

We propose that a controlled electrochemical generation of oxygen radicals is capable to address the above-mentioned challenge, as electrochemical redox process provides a sustained method of replenishing radical species at ambient conditions without sacrificing their high reactivities ${ }^{19,20}$. While $\mathrm{d}^{0}$ early transition metal centers are not known to be directly oxidizable, we accidentally found that electrochemical oxidation of $\mathrm{d}^{0}$ early transition metal-oxo species in $68-98 \% \mathrm{H}_{2} \mathrm{SO}_{4}$ yields cation

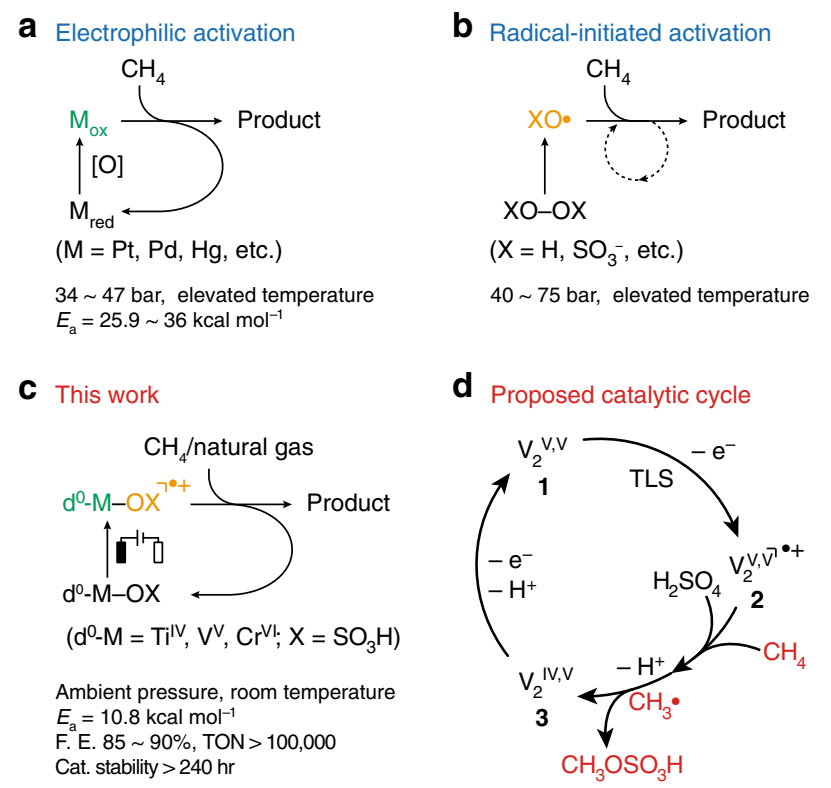

Fig. 1 Pathways to $\mathbf{C H}_{\mathbf{4}}$ functionalization. a-c Representative approaches of $\mathrm{CH}_{4}$ functionalization based on electrophilic activation ${ }^{3-6}$ (a) and radical chain mechanism ${ }^{8-10}(\mathbf{b})$, in comparison with the proposed electrocatalytic method (c). d The proposed catalytic cycle of electrocatalytic $\mathrm{CH}_{4}$ activation with $d^{0}$ vanadium (V)-oxo dimer (1). $M_{\text {red }}$ and $M_{o x}$, reduced and oxidized metal active sites, respectively; [O], chemical or electrochemical oxidation; $E_{a}$, activation energy; $\mathrm{d}^{0}-\mathrm{M}, \mathrm{d}^{0}$ early transition metal species; F.E. Faradaic efficiency, TON turnover number, TLS turnover-limiting step. radicals on the sulfonic ligand that selectively activate $\mathrm{CH}_{4}$ at ambient pressure and room temperature (Fig. 1c). Here, we report $\mathrm{d}^{0}$ vanadium $(\mathrm{V})$-oxo dimer $\left(\mathrm{V}_{2} \mathrm{~V}, \mathrm{~V}, \mathbf{1}\right)^{21}$ as the model catalyst for mechanistic understanding (Fig. 1d). As the tentative turnover-limiting step (TLS) uncommon for homogenous electrocatalysis, an electrochemical one-electron removal of $\mathbf{1}$ yields a cation radical $\left(\mathrm{V}_{2} \mathrm{~V}, \mathrm{~V} \bullet+, 2\right)$ reactive towards $\mathrm{CH}_{4}$, while the catalytic cycle is fulfilled by additional electrochemical oxidation and cation radical regeneration.

\section{Results}

Discovery of ambient $\mathrm{CH}_{4}$ activation with vanadium (V)-oxo catalyst. The $\mathrm{d}^{0}$ vanadium (V)-oxo catalyst (1) was prepared by dissolving $\mathrm{V}_{2} \mathrm{O}_{5}$ in $98 \% \mathrm{H}_{2} \mathrm{SO}_{4}$. Cyclic voltammograms of $10 \mathrm{mM}$ 1 in $98 \% \mathrm{H}_{2} \mathrm{SO}_{4}$ under 1-bar nitrogen gas $\left(\mathrm{N}_{2}\right)$ (blue), 1-bar $\mathrm{CH}_{4}$ (red), and a blank control (black) are displayed in Fig. $2 \mathrm{a}$ at $25^{\circ} \mathrm{C}$ on a platinum $(\mathrm{Pt})$ working electrode. A quasi-reversible peak corresponding to $\mathrm{V}^{\mathrm{V}} / \mathrm{V}^{\mathrm{IV}}$ redox couple was observed with a midpoint potential $E_{1 / 2}=0.644 \mathrm{~V}$ vs. $\mathrm{Hg}_{2} \mathrm{SO}_{4} / \mathrm{Hg}$ reference electrode, with a diffusion coefficient $D=2.18 \times 10^{-11} \mathrm{~m}^{2} \mathrm{~s}^{-1}$ for 1 based on Randles-Savcik analysis (Supplementary Fig. 1a, b) ${ }^{22}$. Additional oxidation current of 1 was observed at the electrochemical potential $E>1.6 \mathrm{~V}$ vs. $\mathrm{Hg}_{2} \mathrm{SO}_{4} / \mathrm{Hg}$, and such an oxidation current is larger in $\mathrm{CH}_{4}$ than in $\mathrm{N}_{2}$. This observation suggests that $\mathbf{1}$ can be further oxidized electrochemically and $\mathrm{CH}_{4}$ is likely to react with the resultant oxidized species. Bulk electrolysis in $98 \% \mathrm{H}_{2} \mathrm{SO}_{4}$ under 1-bar $\mathrm{CH}_{4}$ was conducted at a $E=$ $2.255 \mathrm{~V}$ vs. $\mathrm{Hg}_{2} \mathrm{SO}_{4} / \mathrm{Hg}$ for $6 \mathrm{~h}$ with an electrode of fluorinedoped tin oxide (Supplementary Fig. 1c). The liquid composition after electrolysis were analyzed by ${ }^{1} \mathrm{H}$ and ${ }^{13} \mathrm{C}$ nuclear magnetic resonance (NMR) spectroscopy. $\mathrm{CH}_{3} \mathrm{OSO}_{3} \mathrm{H}$, which yields methanol after hydrolysis ${ }^{11}$, was observed at chemical shift $\delta=$ $3.34 \mathrm{ppm}$ in ${ }^{1} \mathrm{H}$ NMR after electrolysis with $10 \mathrm{mM} 1$ under $\mathrm{CH}_{4}$ (red in Fig. 2b). No gaseous or liquid products other than $\mathrm{CH}_{3} \mathrm{OSO}_{3} \mathrm{H}$ were observed as a product of $\mathrm{CH}_{4}$ oxidation within our detection limit via NMR spectroscopy (Fig. 2b), mass spectroscopy (Supplementary Fig. 2a, b) and gas chromatography (Supplementary Fig. 3). Organic products were not detected in the absence of 1 under $\mathrm{CH}_{4}$ (black), with $10 \mathrm{mM} 1$ under $\mathrm{N}_{2}$ (blue in Fig. 2b), or at a less anodic potential $\left(E=1.855 \mathrm{~V}\right.$ vs. $\mathrm{Hg}_{2} \mathrm{SO}_{4} /$ $\mathrm{Hg}$ ) (Supplementary Fig. 2d). These data confirm that $\mathrm{CH}_{4}$ undergoes a two-electron oxidation into $\mathrm{CH}_{3} \mathrm{OSO}_{3} \mathrm{H}$, initiated by the electrochemical oxidation of $\mathbf{1}$. The absence of a well-defined redox wave preceding the current onset in Fig. 2a suggests either a homogenous electrocatalysis limited by the rate of electron transfer or the occurrence of materials deposition during the scans of cyclic voltammetry. The measurement of X-ray photoelectron spectra on a FTO electrode after 6-h electrolysis with $10 \mathrm{mM} 1$ detected no residual $\mathrm{V}$ signal on the electrode (Supplementary Fig. 4) despite the observed $\mathrm{CH}_{3} \mathrm{OSO}_{3} \mathrm{H}$ formation (1-bar $\mathrm{CH}_{4}, E=2.255 \mathrm{~V}$ vs. $\mathrm{Hg}_{2} \mathrm{SO}_{4} / \mathrm{Hg}$ ). Reusing this vanadiumexposed FTO electrode for 6-h electrolysis in neat $98 \% \mathrm{H}_{2} \mathrm{SO}_{4}$ under $\mathrm{CH}_{4}$ yielded no $\mathrm{CH}_{4}$ activation. These results suggest a likely homogenous electrocatalysis limited by charge transfer. We also conducted isotope-labeling experiments by introducing ${ }^{13} \mathrm{CH}_{4}$ as the substrate at 1-bar pressure. The introduction of ${ }^{13} \mathrm{CH}_{4}$ in lieu of $\mathrm{CH}_{4}$ of natural abundance leads to the surge of ${ }^{13} \mathrm{CH}_{3} \mathrm{OSO}_{3} \mathrm{H}$ signal at $\delta=58.6 \mathrm{ppm}$ in ${ }^{13} \mathrm{C}$ NMR after electrolysis (Fig. 2c). An introduction of a $50 \%{ }^{13} \mathrm{C}$-enriched $\mathrm{CH}_{4}$ yields not only the same peak in ${ }^{13} \mathrm{C}$ NMR but also a triplet in ${ }^{1} \mathrm{H}$ NMR with ${ }^{13} \mathrm{C}-{ }^{1} \mathrm{H}$ doublet and ${ }^{12} \mathrm{C}-{ }^{1} \mathrm{H}$ singlet at a 1:1 ratio of integration area (Supplementary Fig. 5). The optical absorption spectra of the solution before and after electrolysis were identical to each other (Supplementary Fig. 2e), implying that $\mathbf{1}$ as a catalyst was regenerated after electrolysis. 

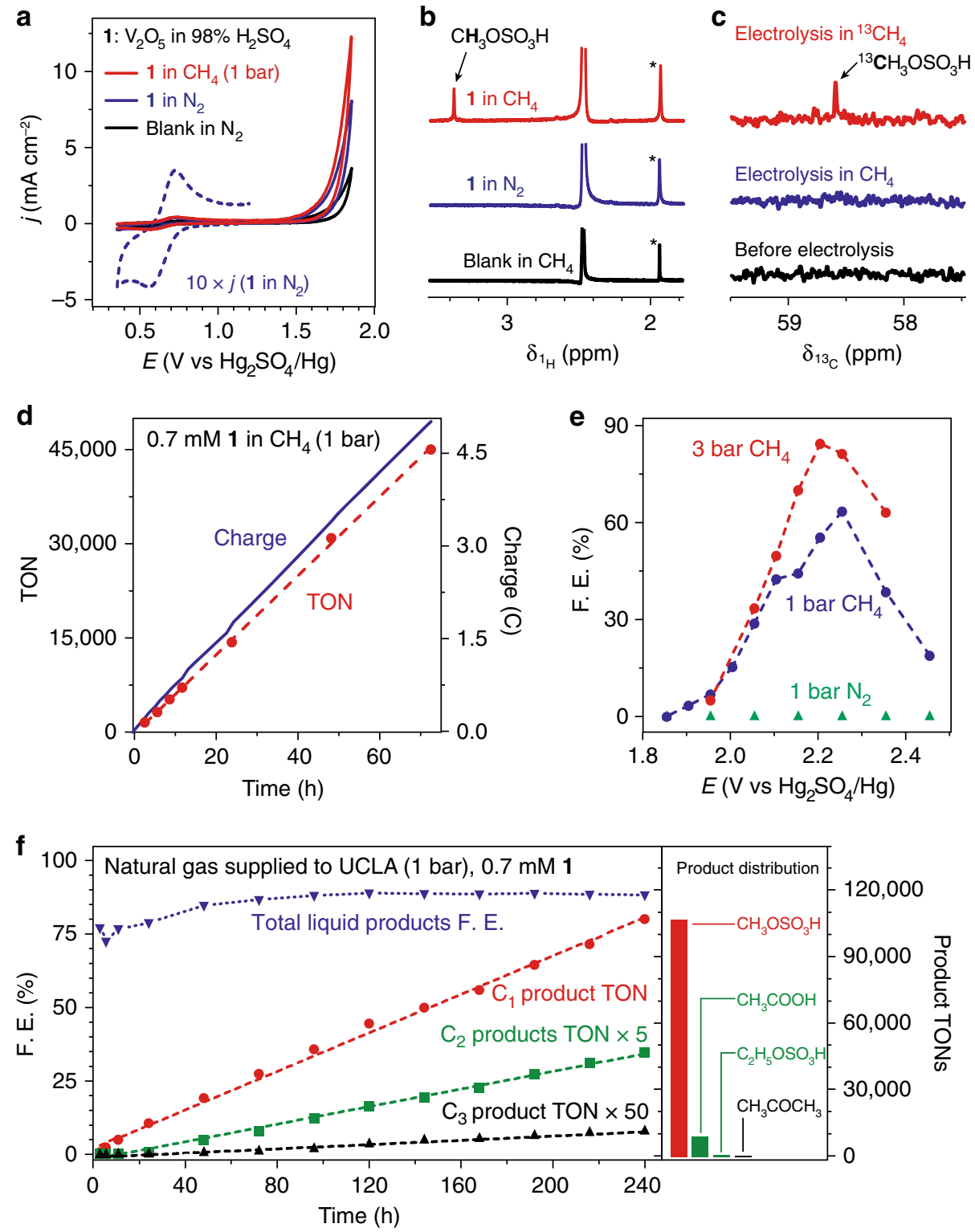

Fig. 2 Electrochemical functionalization of $\mathbf{C H}_{\mathbf{4}}$ and natural gas mixture. $\mathbf{a}$, b Cyclic voltammograms (a) and ${ }^{1} \mathrm{H}$ NMR spectra of liquid samples after 6-h electrolysis (b) for $10 \mathrm{mM} \mathbf{1}$ in 1-bar $\mathrm{CH}_{4}$ (red), $10 \mathrm{mM} \mathbf{1}$ in 1-bar $\mathrm{N}_{2}$ (blue), and blanks without $\mathbf{1}$ (black). Dashed blue, current density (j) of blue trace magnified by a factor of 10. *, internal standard acetic acid. ${ }^{13} \mathrm{C} \mathrm{NMR} \mathrm{spectra} \mathrm{of} \mathrm{samples} \mathrm{before} \mathrm{(black)} \mathrm{and} \mathrm{after} \mathrm{electrolysis} \mathrm{with}{ }^{13} \mathrm{CH}_{4}(\mathrm{red})$ and $\mathrm{CH}_{4}$ of natural abundance (blue), respectively. d Calculated TONs (red) and electric charges passed (blue) versus the duration of electrolysis. e F.E. of $\mathrm{CH}_{4}$ functionalization in $10 \mathrm{mM} 1$ vs. electrode potential $E$ under 1-bar $\mathrm{N}_{2}$ (green), 1-bar $\mathrm{CH}_{4}$ (blue) and 3-bar $\mathrm{CH}_{4}$ (red). f Cumulative TONs for $\mathrm{C}_{1}$ (red), $\mathrm{C}_{2}$ (green, multiplied by a factor of 5), and $\mathrm{C}_{3}$ products (black, multiplied by a factor of 50) as well as F.E. values of total liquid products (blue) are plotted against the duration of bulk electrolysis. TON values for $\mathrm{CH}_{3} \mathrm{OSO}_{3} \mathrm{H}$ (red), $\mathrm{CH}_{3} \mathrm{COOH}$ plus $\mathrm{C}_{2} \mathrm{H}_{5} \mathrm{OSO}_{3} \mathrm{H}$ (green), and $\mathrm{CH}_{3} \mathrm{COCH}_{3}$ (black) within $240 \mathrm{~h}$ are shown on the right, respectively. Natural gas mixture supplied by SoCalGas was used as the substrate at ambient pressure. Trace products beyond $\mathrm{C}_{3}$ were also observed. $100 \mathrm{mV} \mathrm{s}^{-1}$ and Pt working electrode in (a); FTO working electrode in (b) to (f), and $E=2.255 \mathrm{~V}$ vs. $\mathrm{Hg}_{2} \mathrm{SO}_{4} / \mathrm{Hg}$ in (b) to (d), and (f).

Electrochemical $\mathrm{CH}_{4}$ and natural gas functionalization. The electrocatalysis with $\mathbf{1}$ is durable and selective for functionalization of $\mathrm{CH}_{4}$ with high turnover numbers (TONs) and turnover frequencies (TOFs). Bulk electrolysis was conducted with $0.7 \mathrm{mM}$ 1 at $25^{\circ} \mathrm{C}$ under 1-bar pressure of $\mathrm{CH}_{4}$. Liquid aliquots at different time points were analyzed, and the electrochemical TONs were calculated based on the existing method ${ }^{19,23}$. Figure $2 \mathrm{~d}$ displayed the amount of electric charge and the calculated TONs as a function of electrolysis duration. A linear correlation suggests a durable catalyst of TON up to 45,000 in $72 \mathrm{~h}$ without signs of catalyst degradation. We also investigated the Faradaic efficiency (F.E.), defined as the selectivity of converting $\mathrm{CH}_{4}$ into $\mathrm{CH}_{3} \mathrm{O}$ $\mathrm{SO}_{3} \mathrm{H}$ based on the amount of electric charge, as function of $E$ at $25^{\circ} \mathrm{C}$. In $10 \mathrm{mM} 1$ (Fig. 2e), the absence of $\mathrm{CH}_{4}$ leads to no product formation (green), and under 1-bar $\mathrm{CH}_{4}$ an optimal F.E. $=63.5 \%$ when $E=2.255 \mathrm{~V}$ vs. $\mathrm{Hg}_{2} \mathrm{SO}_{4} / \mathrm{Hg}$ (blue). We found that the reaction selectivity is limited by the mass transport and a limited solubility of $\mathrm{CH}_{4}$ in solvent $(\sim 1 \mathrm{mM})^{11}$. When $\mathrm{CH}_{4}$ pressure increased to 3 bar, the optimal F.E. $=84.5 \%$ at $E=2.205$ $\mathrm{V}$ vs. $\mathrm{Hg}_{2} \mathrm{SO}_{4} / \mathrm{Hg}$ (red in Fig. 2e). The corresponding TOFs of 1 as an electrocatalyst are 483 and $1336 \mathrm{~h}^{-1}$ for $\mathrm{CH}_{4}$ at 1 and 3-bar pressures, respectively, which are conservative and underestimated given the nature of our analysis (Supplementary Note 1). The measured TOF values at room temperature compare quite favorably with other reported catalysts at elevated temperatures and high pressures (Supplementary Table 1). 
We expanded the substrate scope from $\mathrm{CH}_{4}$ to ethane $\left(\mathrm{C}_{2} \mathrm{H}_{6}\right)$, propane $\left(\mathrm{C}_{3} \mathrm{H}_{8}\right)$, and ultimately natural gas mixture at 1-bar pressure. $\mathrm{C}_{2} \mathrm{H}_{6}$ was oxidized to a mixture of acetic acid $\left(\mathrm{CH}_{3} \mathrm{COOH}\right)$ and ethyl bisulfate $\left(\mathrm{C}_{2} \mathrm{H}_{5} \mathrm{OSO}_{3} \mathrm{H}\right)$ (Supplementary Fig. 6a), whose TOF values are 297 and $235 \mathrm{~h}^{-1}$, respectively. $\mathrm{C}_{3} \mathrm{H}_{8}$ was converted to mostly isopropyl bisulfate $\left(i-\mathrm{C}_{3} \mathrm{H}_{7} \mathrm{OSO}_{3} \mathrm{H}\right)$ with trace acetone $\left(\mathrm{CH}_{3} \mathrm{COCH}_{3}\right)$ in a 6-h electrolysis (Supplementary Fig. 6b), with TOF values of 962 and $2 \mathrm{~h}^{-1}$, respectively. One challenge in designing a process of natural gas utilization is to balance the low reactivity of the major component $\mathrm{CH}_{4}$ with the high reactivity of minor light alkane components ${ }^{24}$, as in some cases the latter substrates can react 100-time faster than $\mathrm{CH}_{4}{ }^{25}$. The similar TOF values among $\mathrm{CH}_{4}, \mathrm{C}_{2} \mathrm{H}_{6}$, and $\mathrm{C}_{3} \mathrm{H}_{8}$ reported here renders 1 a suitable candidate of direct natural gas utilization at ambient conditions without much upstream separation.

Natural gas supplied to UCLA via pipeline by SoCalGas ${ }^{26}$ was used as the substrate of electrolysis $\left(E=2.255 \mathrm{~V}\right.$ vs. $\left.\mathrm{Hg}_{2} \mathrm{SO}_{4} / \mathrm{Hg}\right)$ with $0.7 \mathrm{mM} 1$ in $98 \% \mathrm{H}_{2} \mathrm{SO}_{4}$ at room temperature and ambient pressure. Powered by electricity, natural gas was oxidized into organic chemicals while dioxygen in air was reduced on the counter electrode, fulfilling a partial oxidation of natural gas with air with a net reaction of $\mathrm{CH}_{4}+1 / 2 \mathrm{O}_{2}+\mathrm{H}_{2} \mathrm{SO}_{4} \rightarrow \mathrm{CH}_{3} \mathrm{OSO}_{3} \mathrm{H}$ $+\mathrm{H}_{2} \mathrm{O}$. The yielded products mainly consist of $\mathrm{CH}_{3} \mathrm{OSO}_{3} \mathrm{H}$ from $\mathrm{CH}_{4}, \mathrm{CH}_{3} \mathrm{COOH}$, and $\mathrm{C}_{2} \mathrm{H}_{5} \mathrm{OSO}_{3} \mathrm{H}$ from $\mathrm{C}_{2} \mathrm{H}_{6}$, and $\mathrm{CH}_{3} \mathrm{COCH}_{3}$ from $\mathrm{C}_{3} \mathrm{H}_{8}$ in the natural gas. The TONs of $\mathrm{C}_{1}-\mathrm{C}_{3}$ products reached about 107,000, 9300, and 200 within $240 \mathrm{~h}$, respectively (Fig. 2f) with the final concentration of $\mathrm{CH}_{3} \mathrm{OSO}_{3} \mathrm{H}$ approaching $10 \mathrm{mM}$ (Supplementary Fig. 7). The observed one-order-ofmagnitude difference between 1 and $\mathrm{CH}_{3} \mathrm{OSO}_{3} \mathrm{H}$ product again supports the catalytic feature of our observation. The total F.E. of all liquid products remain stable at around $90 \%$ during electrolysis after an initial induction period (Fig. 2f, Supplementary Table 2). The linear relationship between TONs and electrolysis durations suggest that $\mathbf{1}$ remains active and is tolerant to the impurities in natural gas mixture. Previous analysis suggests that a lower $\mathrm{H}_{2} \mathrm{SO}_{4}$ concentration in the electrolyte, ideally below $80 \%$, is needed for industrial implementation ${ }^{11}$. This requirement is against the thermodynamic limit of reactions in $\mathrm{H}_{2} \mathrm{SO}_{4}$ with $\mathrm{SO}_{3}$ as the oxidant ${ }^{11}$. Yet we found that 1 remains active towards $\mathrm{CH}_{4}$ functionalization in aqueous solution with $\mathrm{H}_{2} \mathrm{SO}_{4}$ concentrations as low as $68 \%$ under $25^{\circ} \mathrm{C}$ and 1 bar $\mathrm{CH}_{4}$ (Supplementary Fig. 6c), yielding a mixture of methanol and $\mathrm{CH}_{3} \mathrm{OSO}_{3} \mathrm{H}$ (Supplementary Fig. 6d). The robustness under prolonged operation and the applicability in diluted $\mathrm{H}_{2} \mathrm{SO}_{4}-\mathrm{H}_{2} \mathrm{O}$ mixed solvent renders the catalyst potentially suitable to be employed to functionalize natural gas with minimal maintenance.

Scale-up potential over vanadium (V)-oxo electrocatalyst. The reported catalyst $\mathbf{1}$ is also capable to yield high product concentrations amenable for practical implementations. Due to the limited solubility of $\mathrm{CH}_{4}$ in the solvent within current batch reactor ${ }^{11}$, electrocatalytic experiments of higher product concentrations were conducted under room temperature at 11-bar $\mathrm{CH}_{4}$ pressure, in order to mitigate the mass transport issue of limited gas solubility (vide supra) (Supplementary Fig. 7). A 72-h electrolysis leads to a $\mathrm{CH}_{3} \mathrm{OSO}_{3} \mathrm{H}$ concentration of $\sim 110 \mathrm{mM}$ with F.E. $=81.2 \%\left(E=2.376 \mathrm{~V}\right.$ vs. $\left.\mathrm{Hg}_{2} \mathrm{SO}_{4} / \mathrm{Hg}\right)$. Adding $1 \mathrm{M}$ $\mathrm{CH}_{3} \mathrm{OSO}_{3} \mathrm{H}$ prior to the electrocatalysis under the same condition does not hinder the catalysis or decompose the pre-added $\mathrm{CH}_{3} \mathrm{OSO}_{3} \mathrm{H}$. A single-pass conversion of $1 \%$ was observed in the mixed-flow electrochemical reactor, comparable to the results that lead to electrochemical reduction of $\mathrm{CO}_{2}$ and $\mathrm{CO}$ at nearindustrial level ${ }^{27,28}$. The product concentrations reported here are higher than the ones in other electrocatalysis ${ }^{5,6}$, and suggest that high product concentration of electrocatalysis is attenable. There seems no observable fundamental limit for product concentrations exceeding one mole per liter, a threshold considered suitable for industrial applications ${ }^{11}$.

Kinetics investigation of electrochemical $\mathrm{CH}_{4}$ functionalization. The attractive feature of catalyst 1 led us to investigate the underlying mechanism during electrolysis with $\mathrm{CH}_{4}$ as the substrate. The current density corresponding $\mathrm{CH}_{3} \mathrm{OSO}_{3} \mathrm{H}$ formation $\left(j_{\mathrm{CH} 4}\right)$, a surrogate of $\mathrm{CH}_{4}$-activating rate, was investigated as a function of catalyst concentration [1] (Fig. 3a), the electrode potential $E$ (Fig. 3b), the partial pressure of $\mathrm{CH}_{4}\left(p_{\mathrm{CH} 4}\right)$ (Fig. 3c), and the temperature $\mathrm{T}$ (Fig. $3 \mathrm{~d}$ ). A linear relationship with a slope $=1.03 \pm 0.08$ between $\log _{10}\left(j_{\mathrm{CH} 4}\right)$ and $\log _{10}([\mathbf{1}])$ suggests that $\mathrm{CH}_{4}$ activation is first-order on 1 (Fig. 3a). When $\log _{10}\left(j_{\mathrm{CH} 4}\right)$ was plotted against $E$ (Fig. 3b), a Tafel slope of about $120 \mathrm{mV} \mathrm{dec}^{-1}$ was observed before $j_{\mathrm{CH} 4}$ plateaus at larger $E$ values as $\mathrm{CH}_{4}$ is depleted near electrode. This suggests that the first electron removal from 1 is the TLS, uncommon for homogeneous electrocatalysis (Supplementary Note 2). The overlapping points under 1 and 3-bar $\mathrm{CH}_{4}$ pressure when $E<2.1 \mathrm{~V}$ vs. $\mathrm{Hg}_{2} \mathrm{SO}_{4} / \mathrm{Hg}$ suggest that $\mathrm{CH}_{4}$ is not involved in the TLS or any pre-equilibrium steps. When $E>2.1 \mathrm{~V}$ vs. $\mathrm{Hg}_{2} \mathrm{SO}_{4} / \mathrm{Hg}$, a linear relationship between $\log _{10}\left(j_{\mathrm{CH} 4}\right)$ and $\log _{10}\left(p_{\mathrm{CH} 4}\right)$ with a slope of $0.91 \pm 0.07$ (Fig. 3c) suggests that $\mathrm{CH}_{4}$ is activated in a first order after the TLS. We also found that the residual current density, the difference between total current density $\left(j_{\text {total }}\right)$ and $j_{\mathrm{CH} 4}$, is independent of $p_{\mathrm{CH} 4}$ (Supplementary Fig. 2c). It further corroborates that no gaseous or liquid products other than $\mathrm{CH}_{3} \mathrm{OSO}_{3} \mathrm{H}$ were generated from $\mathrm{CH}_{4}$ oxidation, and solvent oxidation into $\mathrm{O}_{2}$ and possibly trace persulfate ${ }^{29,30}$ is the only plausible side reaction (vide infra). The Arrhenius plot between $\ln \left(j_{\mathrm{CH} 4}\right)$ and $1 / \mathrm{T}$ yields an apparent activation energy $\left(E_{a}\right)$ as low as $10.8 \pm 0.6 \mathrm{kcal} \mathrm{mol}^{-1}$ (Fig. $3 \mathrm{~d}$ ), consistent with the observed ambient reactivity. When conducting electrolysis of $\mathbf{1}$ in $98 \% \mathrm{D}_{2} \mathrm{SO}_{4}$ with $\mathrm{CH}_{4}$ of natural isotope abundance, ${ }^{2} \mathrm{D}$ and ${ }^{1} \mathrm{H}$ NMR spectra showed no $\mathrm{H} / \mathrm{D}$ exchange in the methyl group of product $\mathrm{CH}_{3} \mathrm{OSO}_{3} \mathrm{H}$ (Supplementary Fig. 6e). This excludes the possible mechanism induced by an electrochemically generated superacid ${ }^{17}$, which should yield significant $H / D$ exchange in the methyl group ${ }^{11}$. In addition, when $\mathrm{CH}_{4}$ was exposed to $\mathbf{1}$ in $98 \% \mathrm{H}_{2} \mathrm{SO}_{4}$ with added $\mathrm{K}_{2} \mathrm{~S}_{2} \mathrm{O}_{8}$ or $\mathrm{H}_{2} \mathrm{O}_{2}$ in the absence of electricity, $\mathrm{CH}_{4}$ functionalization was not observed at ambient conditions (Supplementary Fig. 6f). This illustrates that it is difficult for chemical method to sustainably generate reactive radical intermediates at room temperature, which necessitates our use of electrochemistry as proposed before. It also shows that the possible formation of peroxo species including peroxoacids is not contributing to the observed reactivity. When the electrolyte was switched from $98 \% \mathrm{H}_{2} \mathrm{SO}_{4}$ to oleum with $20 \% \mathrm{SO}_{3}$, a 5.4:1 molar ratio between $\mathrm{CH}_{3} \mathrm{SO}_{3} \mathrm{H}$ and $\mathrm{CH}_{3} \mathrm{OSO}_{3} \mathrm{H}$ was observed after electrocatalysis (Supplementary Fig. 8). This indicates the formation of $\mathrm{CH}_{3} \bullet$ radical during the catalysis, which yields $\mathrm{CH}_{3} \mathrm{SO}_{3} \mathrm{H}$ in the presence of $\mathrm{SO}_{3}{ }^{9}$. Overall, our experimental data support an electrochemical catalysis of low activation energy. After a turnoverlimiting one-electron oxidation of $\mathbf{1}$, the oxidized species undergoes a first-order $\mathrm{C}-\mathrm{H}$ activation in $\mathrm{CH}_{4}$ and a formation of $\mathrm{CH}_{3}$. radical (Fig. 1d).

Unveiling dimer structure of vanadium (V)-oxo catalyst. Despite its ease of preparation, the structural information of $\mathbf{1}$ is not well understood. It was hypothesized to be $\mathrm{V}_{2} \mathrm{~V}, \mathrm{~V}$ dimer with two terminal $\mathrm{V}^{\mathrm{V}} \equiv \mathrm{O}$ moieties connected by a bridging oxo ${ }^{21}$. We measured 1's optical absorption (Supplementary Fig. 9a) and the ${ }^{51} \mathrm{~V}$ NMR spectrum (Supplementary Fig. 9b), which confirmed that $\mathbf{1}$ is different from monometallic $\mathrm{VO}_{2}{ }^{+}$species in an 

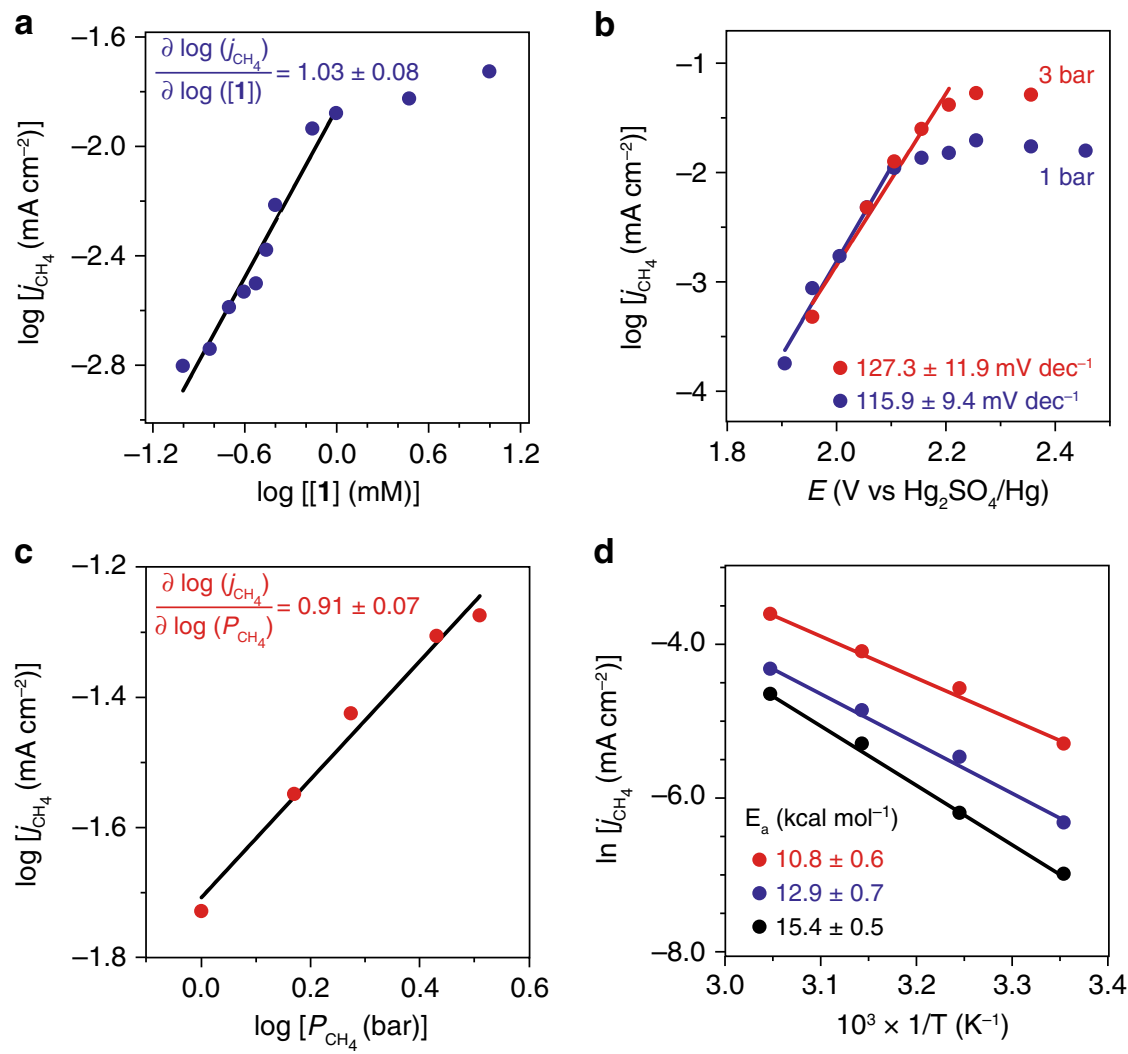

Fig. 3 Electrocatalytic kinetics. a The logarithmic of partial current density for $\mathrm{CH}_{4}$ functionalization, $\log \left(j_{\mathrm{CH} 4}\right)$, versus the logarithmic of $\mathbf{1}$ 's concentration, $\log ([\mathbf{1}])$. b $\log \left(j_{\mathrm{CH} 4}\right)$ vs. $E$ under $\mathrm{CH}_{4}$ pressures of 1 bar (blue) and 3 bar (red) with the fitted Tafel slopes displayed. $\mathbf{c}$ Log $\left(j_{\mathrm{CH} 4}\right)$ vs. the logarithmic of $\mathrm{CH}{ }_{4}$ pressure, $\log \left(p_{\mathrm{CH} 4}\right)$. d The natural logarithmic of partial current density for $\mathrm{CH}_{4}$ functionalization, $\ln \left(j_{\mathrm{CH} 4}\right)$, vs. inverse of temperature, $\mathrm{T}^{-1}$, at $1.955 \mathrm{~V}$ (black), $2.005 \mathrm{~V}$ (blue), and $2.055 \mathrm{~V}$ (red) vs. $\mathrm{Hg}_{2} \mathrm{SO}_{4} / \mathrm{Hg}$, respectively. The corresponding apparent activation energies $\left(E_{a}\right)$ are displayed. Unless noted specifically, $25^{\circ} \mathrm{C}, 10 \mathrm{mM} 1$ in $98 \% \mathrm{H}_{2} \mathrm{SO}_{4}, E=2.255 \mathrm{~V}$ vs. $\mathrm{Hg}_{2} \mathrm{SO}_{4} / \mathrm{Hg}, p_{\mathrm{CH} 4}=1$ bar, data recorded from 6-h bulk electrolysis.

aqueous medium Density functional theory (DFT) calculations suggest that $\mathbf{1}$ may exist as two isomers, $\mathbf{1 a}$ and $\mathbf{1 b}$ (Fig. 4a), with a calculated energy difference of $1.2 \mathrm{kcal} \mathrm{mol}^{-1}$. In an attempt to obtain the correct structure of $\mathbf{1}$ and real conformation in solution, $\mathrm{X}$-ray absorption spectroscopy of $\mathrm{V}$ atom was conducted for $10 \mathrm{mM} 1$ in $98 \% \mathrm{H}_{2} \mathrm{SO}_{4}$, solid $\mathrm{V}_{2} \mathrm{O}_{5}$, and metallic $\mathrm{V}$ foil (solid red, dashed blue, and dashed yellow in Fig. $4 \mathrm{~b}, \mathrm{c}$, respectively). We carried out a least-square-regression analysis on X-ray absorption near-edge structure (XANES) for the threshold positions, the first peak in the derivative spectra, of $\mathrm{VO}, \mathrm{V}_{2} \mathrm{O}_{3}, \mathrm{VO}_{2}$, and $\mathrm{V}_{2} \mathrm{O}_{5}$ to determine the electronic structure and oxidation state of vanadium in 1 (Supplementary Fig. 9c) ${ }^{31}$. The electronic structure of vanadium in 1 remains similar to that of vanadium in $\mathrm{V}_{2} \mathrm{O}_{5}$, confirming the $\mathrm{d}^{0}$ electronic structure of vanadium. The extended $\mathrm{X}$-ray absorption fine structure (EXAFS) can offer coordination information of absorbing atoms by extracting the structural parameters. As shown in Fig. 4c, the absence of noticeable peaks in the region beyond $4 \AA$ (solid red), compared with those of $\mathrm{V}_{2} \mathrm{O}_{5}$ and $\mathrm{V}$ foil (dashed blue and dashed yellow, respectively), indicates that $\mathbf{1}$ is a complex homogenously dispersed in the solvent. The peak around $1.56 \AA$ in l's EXAFS spectrum (gray area) is attributed to the $\mathrm{V}-\mathrm{O}$ bonds, following the assignment of $\mathrm{V}-\mathrm{O}$ bonds in the $\mathrm{V}_{2} \mathrm{O}_{5}$ sample. While this comparison provides some information, the general low symmetries of the vanadium-based species prevent us from gaining detailed structural information of $\mathbf{1}$ solely based on EXAFS data ${ }^{32}$. To this end, we conducted the fitting of 1's V K-edge EXAFS spectrum combining the structure suggested by DFT calculations (shown in Fig. 4d). It reveals that the central $\mathrm{V}$ atoms are penta-coordinated by $\mathrm{O}$ atoms with three types of $\mathrm{V}-\mathrm{O}$ bond lengths $(1.58,1.68$, and $1.96 \AA)$ in the first coordinated shell, with a bridging oxo with a V-O bond length of $1.68 \AA$. We note that the EXAFS of 1 suggests a unique coordination environment 2.0-3.5 $\AA$ away from $\mathrm{V}$ atom (blue area), which is different from the monometallic $\mathrm{VO}_{2}{ }^{+}$species in aqueous medium (Supplementary Fig. 9d). The fitting results of second shell (blue area) indicate that consistent with the predicted structure 1a, there are not only three $\mathrm{S}$ atoms in the second shell (2.73 and $3.13 \AA$ ) but also one $\mathrm{V}$ atom at the distance of $3.27 \AA$ away from the central V atom (Supplementary Table 3). Detailed analysis is provided in the Supplementary information (Supplementary Fig. 9e, f). These results reveal the existence of a hypothesized structure of $\mu$-oxo bridged $\mathrm{V}_{2}^{\mathrm{V}, \mathrm{V}}$ dimer $^{33}$, and suggest that $\mathbf{1 a}$ is the structure of $\mathbf{1}$ in the solution.

Operando characterizations for mechanistic study. Additional operando characterizations were conducted to confirm a homogenous electrocatalysis and elucidate identities of immediate species. Operando Raman spectroscopy measures the vibrational spectra of chemical species near the FTO electrode at different values of $E$ in $\mathrm{CH}_{4}$. No spectral changes were observed and the vibrational spectra evidently differs from solid $\mathrm{V}_{2} \mathrm{O}_{5}$ sample (Supplementary Fig. 10). This suggests that there is no detectable heterogeneous intermediate deposited on the FTO electrode during electrocatalysis. Operando XAS spectra of $\mathrm{V}$ atom was also measured at different values of $E$ in $\mathrm{CH}_{4}$. Largely, the XANES and EXAFS spectra (Supplementary Figs. 11 and 12) differ from the ones of solid $\mathrm{V}_{2} \mathrm{O}_{5}$ sample and supports a homogenous electrocatalysis. Yet some information of reaction intermediates is available. The formal oxidation state of $\mathrm{V}$ species, indicative in 
a Possible structures of 1 based on DFT calculations

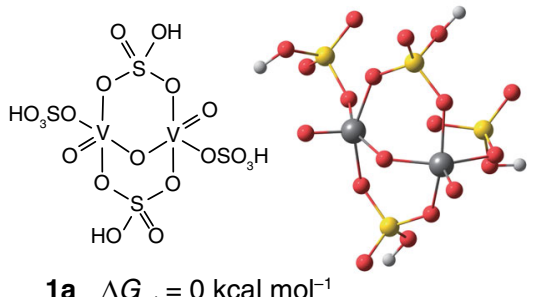

1a $\Delta G_{\text {rel }}=0 \mathrm{kcal} \mathrm{mol}^{-1}$
$1 b$
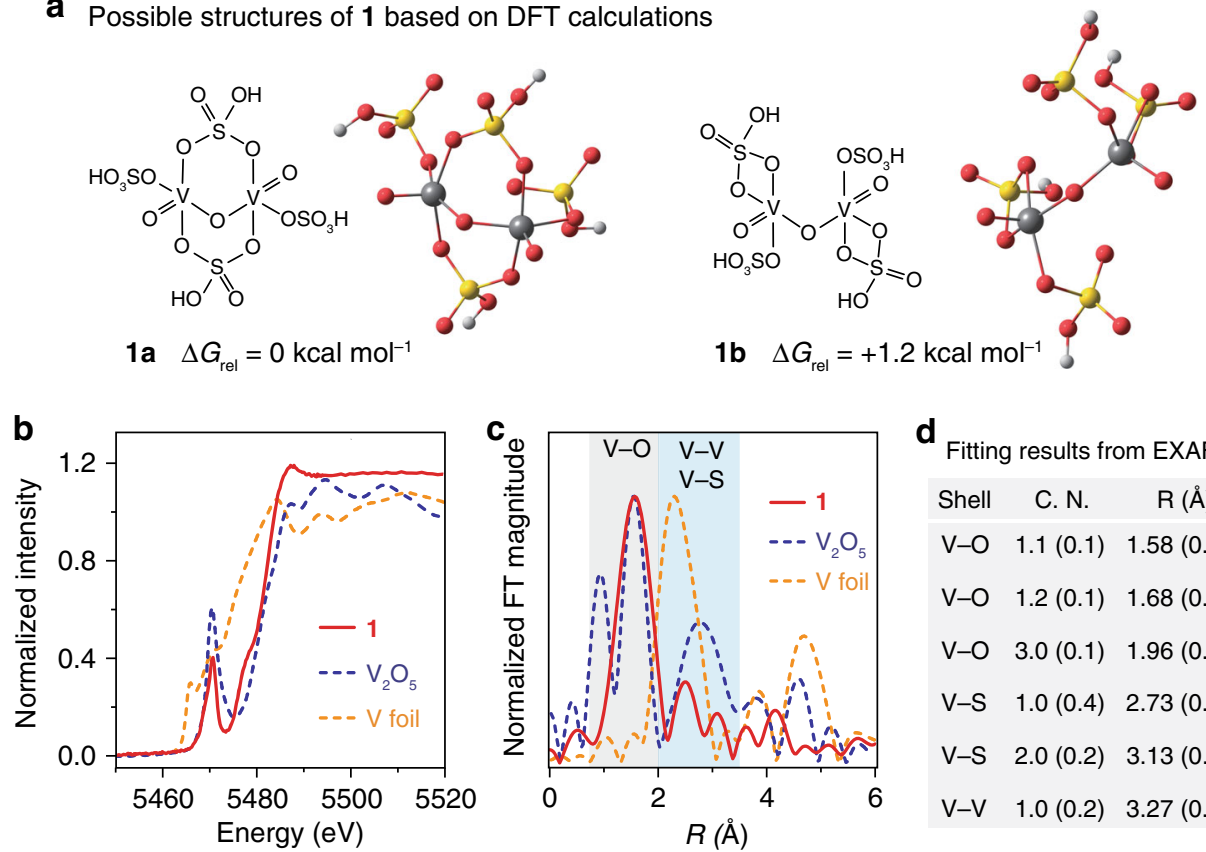

d Fitting results from EXAFS

Shell $\quad$ C. N. R $\quad$ R (Å)

$\mathrm{V}-\mathrm{O} \quad 1.1(0.1) \quad 1.58(0.01)$

$\mathrm{V}-\mathrm{O} \quad 1.2(0.1) \quad 1.68(0.02)$

V-O $3.0(0.1) \quad 1.96(0.01)$

V-S $1.0(0.4) \quad 2.73(0.05)$

V-S $2.0(0.2) \quad 3.13(0.07)$

$\mathrm{V}-\mathrm{V} \quad 1.0(0.2) \quad 3.27(0.05)$

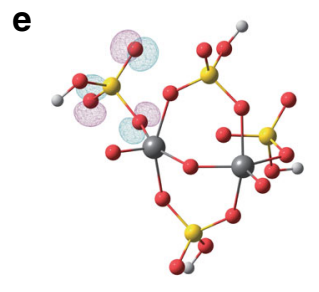

$\mathrm{V}_{2}^{\mathrm{V}, \mathrm{V}}, \mathbf{1 a}$

(HOMO)
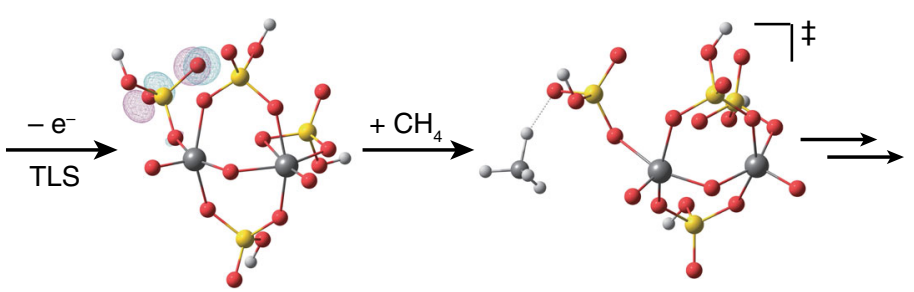

$\mathrm{H}$-atom abstraction

No significant barrier

Overall reaction: $\mathrm{CH}_{4}+\mathrm{H}_{2} \mathrm{SO}_{4} \frac{1,25^{\circ} \mathrm{C}}{98 \% \mathrm{H}_{2} \mathrm{SO}_{4}} \mathrm{CH}_{3} \mathrm{OSO}_{3} \mathrm{H}+2 \mathrm{e}^{-}+2 \mathrm{H}^{+}$

Fig. 4 Structural information of the catalyst and a proposed mechanism. a Possible isomeric structures of $\mathbf{1}$ and their relative energetics based on DFT calculations. b, c Normalized intensity of $\mathrm{V}$ K-edge X-ray absorption near-edge structure (XANES) (b) and extended X-ray absorption fine structure (EXAFS) (c) for $\mathbf{1}$ (solid red), $\mathrm{V}_{2} \mathrm{O}_{5}$ (dashed blue), and metallic $\mathrm{V}$ (dashed yellow). d Calculated coordination number (C.N.) and the distance (R) away from $\mathrm{V}$ atom based on EXAFS results. e Calculated frontier orbitals involved in the TLS and the proposed transition state of $\mathrm{C}-\mathrm{H}$ activation step. HOMO highest occupied molecular orbital, LUMO lowest unoccupied molecular orbital. *Designated when considering spin-orbital coupling, equivalent to singly occupied molecular orbital (SOMO) in restricted formalism.

the pre-edge region of XANES spectra (Supplementary Fig. 11), decreases from +5 to near +4 with increasing value of $E$, contrary to the typical trend observed in heterogeneous catalysts of electrochemical oxidation ${ }^{34}$. This reveals the presence of mixedvalence $V_{2} I V, V$ during catalysis (Supplementary Note 3 ). It also supports a homogenous, diffusion-controlled catalysis, since a hypothetical immobile V(IV) species deposited on the electrode may not have long enough lifetime to be detectable (Supplementary Note 3), given the large thermodynamic driving force of oxidizing V(IV) ( $>1.2 \mathrm{~V}$ from Fig. 2a). The pre-edge region also witnesses a broadening and intensity decrease of the pre-edge peak concurrent with the increase of $E$ and the observation of electrocatalytic $\mathrm{CH}_{4}$ functionalization (Supplementary Fig. 11). This suggests an increase of coordination symmetry near $\mathrm{V}$ atom and possibly a loss of sulfonic ligand ${ }^{31}$. The operando EXAFS results (Supplementary Fig. 12) also displays a decrease of average coordination number of sulfonic ligands per $\mathrm{V}$ atom concurrent with increasing $E$ values. Those results imply that the bisulfate group in $\mathrm{CH}_{3} \mathrm{OSO}_{3} \mathrm{H}$ likely originate from the vanadium catalyst, a plausible radical rebound mechanism ${ }^{35}$.
Proposed electrocatalytic cycle with vanadium (V)-oxo dimer. Combining experimental and computational results, we established a proposed catalytic cycle of $\mathbf{1}$ for $\mathrm{CH}_{4}$ functionalization (Fig. 1d) despite its uncommon assignment of TLS that warrants additional investigation (Supplementary Note 2). A turnover-limiting electrochemical oxidation of $\mathbf{1 a}$ removes one electron from $\mathrm{O} 2 \mathrm{p}$ orbitals in the sulfonic ligand, which is calculated as the highest occupied molecular orbital (HOMO) of $\mathbf{1 a}$ (Fig. 4e). The resultant cation radical $\mathbf{2}$ is predicted to possess an empty frontier spin-orbital on the same $\mathrm{O} 2 \mathrm{p}$ orbitals (lowest unoccupied molecular orbital (LUMO) of 2 in Fig. $4 \mathrm{e}$ ), which is postulated to initiate $\mathrm{H}$-atom abstraction from $\mathrm{CH}_{4}$. DFT calculations predict reaction trajectory between 2 and $\mathrm{CH}_{4}$ without significant energy barrier (Fig. 4e, Supplementary Fig. 13a). This is consistent with our experimental observation that the TLS is the one-electron oxidation of 1 other than the step of $\mathrm{C}-\mathrm{H}$ activation (Supplementary Note 2). The calculated barrier-less $\mathrm{C}-\mathrm{H}$ activation also helps explain the similar TOFs toward various light alkanes in the natural gas $^{24}$. Currently, we were unable to experimentally characterize 
2 and the $\mathrm{H}$-atom abstraction step due to its transient nature, which will be of our research focus in the future. Yet the subsequent steps of $\mathrm{CH}_{4}$ functionalization seems to proceed with the formation of $\mathrm{CH}_{3}$. and a radical rebound process ${ }^{35}$. This leads to a two-electron oxidation and $\mathrm{CH}_{3} \mathrm{OSO}_{3} \mathrm{H}$ formation with a ligand loss on a $V_{2}{ }^{I V}, V$ dimer (3), which will be readily re-oxidized electrochemically to regenerate 1 (Fig. 1d, Supplementary Fig. 14).

Exploration of molecular and material variants for vanadium (V)-oxo catalyst. DFT calculations of the atomic charges ${ }^{36}$ suggest that cation radical 2 is stabilized thanks to orbital delocalization, in comparison to the scenario when one electron was removed from sulfuric acid (Supplementary Fig. 13b, c). This is consistent with the results that the calculated ionization energies of 1a is lower by $12-14 \mathrm{kcal} \mathrm{mol}^{-1}$ than that of sulfuric acid. This implies that the metal-oxo centers as carrier of sulfonic ligands stabilize the electrochemically generated cation radical, at the same time maintain a cation radical reactive enough for ambient $\mathrm{CH}_{4}$ functionalization. Other $\mathrm{d}^{0}$ early transition-metal-oxo species can possess similar reactivities. We found that $\mathrm{d}^{0}$ metal-oxo

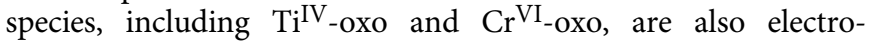
chemically active towards functionalizing $\mathrm{CH}_{4}$ at ambient conditions (Supplementary Fig. 15). A more extensive survey over the first half of the Period 4 elements except Sc indicates that only $\mathrm{Ti}$, $\mathrm{V}, \mathrm{Cr}$, and possibly $\mathrm{Mn}$ display similar reactivities (Supplementary Fig. 16). It suggests the strategy of employing $\mathrm{d}^{0}$ early transition-metal-oxo species is generally applicable for ambient electrochemical functionalization of natural gas. As such a general trend of reactivity was not observed before, we posit our electrochemical approach may offer new perspective towards the challenge of $\mathrm{CH}_{4}$ functionalization.

Practically, a heterogeneous catalyst variant may also be desirable. While $\mathbf{1}$ is characterized as a homogenous catalyst, we found a two-dimensional layered material, $\mathrm{VOPO}_{4} \cdot 2 \mathrm{H}_{2} \mathrm{O}(4)$ with exposed V-oxo edges ${ }^{37}$ (Supplementary Fig. 17a, b), acts as a heterogeneous variant of $\mathbf{1}$ in $98 \% \mathrm{H}_{2} \mathrm{SO}_{4}$ (Supplementary Fig. $17 c, d)$. This preliminary result suggests that even within the same metal-oxo system, the catalyst subsequently its reactivity can be tuned with additional materials design and engineering. This heterogenous variant also simplifes product separation in downstream process, thanks to the absence of vanadium in the liquid phase.

\section{Discussion}

Overall, the general tunability of catalyst composition may herald better catalysts with higher TOF, lower oxidation potential, as well as versatile design of the overall process. The ambient condition of reported catalysis facilitates the use of $\mathrm{O}_{2}$ in ambient air as the terminal electron acceptor, as well as the use of ambient natural gas feedstock for onsite functionalization without a centralized facility. Future research will focus on possible scale-up with the exploration of optimal reaction conditions. The employment of $98 \% \mathrm{H}_{2} \mathrm{SO}_{4}$ or more diluted acids, other than oleum, mitigates the generation of excessive acid in product separation and is attractive for practical application ${ }^{38}$. Additional fundamental and engineering investigation, including the employment of gas diffusion electrode ${ }^{39}$ as well as ingenious design of electrochemical reactors ${ }^{28}$, will further explore the possible application of converting $\mathrm{CH}_{4}$ into commodity chemicals with minimal infrastructure support at remote locations. This will lead to the more efficient usage of green-house gases and reducing their emission into atmosphere.

\section{Methods}

Chemicals and materials. All chemicals were purchased from Sigma-Aldrich, Thermo Fisher Chemical, or VWR International, unless otherwise stated. All chemicals were used as received unless specified. Dimethyl sulfoxide- $\mathrm{d}_{6}\left(\right.$ DMSO- $\left.\mathrm{d}_{6}\right)$ was purchased from Cambridge Isotope Laboratories, Inc. All deionized (DI) water was obtained from a Millipore Milli-Q Water Purification System. Fluorine-doped Tin Oxide (FTO) glass was purchased from Hartford Glass Incorporation. $\mathrm{CH}_{4}(99.5 \%)$ was purchased from Airgas, $\mathrm{C}_{2} \mathrm{H}_{6}(99 \%), \mathrm{C}_{3} \mathrm{H}_{8}$ (98\%), and ${ }^{13} \mathrm{CH}_{4}(99 \%$; 99 atom\% ${ }^{13} \mathrm{C}$ ) were purchased from the Sigma-Aldrich. Natural gas mixture was obtained from the outlet in Molecular Science Building 4211, Department of Chemistry and Biochemistry, UCLA, which is supplied via pipeline by SoCalGas. SRI multiple gas analyzer \#5 gas chromatograph (GC), $8610 \mathrm{C}$ is used to analyze the natural gas mixture. The components are 91.78 mole $\% \mathrm{CH}_{4}, 4.31$ mole $\% \mathrm{C}_{2} \mathrm{H}_{6}, 0.31$ mole $\%$ $\mathrm{C}_{3} \mathrm{H}_{8}, 0.04$ mole $\% n-\mathrm{C}_{4} \mathrm{H}_{10}, 0.03$ mole $\% ~ i-\mathrm{C}_{4} \mathrm{H}_{10}, 0.01$ mole $\% n-\mathrm{C}_{5} \mathrm{H}_{12}, 0.01$ mole $\% ~ i$ $\mathrm{C}_{5} \mathrm{H}_{12}$, and $0.81 \mathrm{~mole} \% \mathrm{CO}_{2}$. Unless specifically noted, reagent-grade $98 \% \mathrm{H}_{2} \mathrm{SO}_{4}$ (VWR BDH3074-3.8LP) was employed as the solvent, which contains 5 ppm of metal impurities. When needed, we also employ high-purity $98 \% \mathrm{H}_{2} \mathrm{SO}_{4}$ (SigmaAldrich 339741), which contains $0.3 \mathrm{ppm}$ of metal impurities as shown in the product certificate.

Chemical and material characterizations. Ultraviolet-visible (UV-vis) spectra was conducted on Hewlett-Packard 8453 UV-vis spectrophotometer. Proton NMR $\left({ }^{1} \mathrm{H}-\mathrm{NMR}\right)$ and carbon NMR $\left({ }^{13} \mathrm{C}-\mathrm{NMR}\right)$ were recorded on a Bruker AV400 $(400 \mathrm{MHz})$ spectrometer. Deuterium NMR $\left({ }^{2} \mathrm{D}-\mathrm{NMR}\right)$ was recorded on a Bruker AV500 $(500 \mathrm{MHz})$ spectrometer. Vanadium NMR ( ${ }^{51} \mathrm{~V}$-NMR) was performed on an Agilent DD2 $600(600 \mathrm{MHz})$ spectrometer. Powder X-ray diffraction (XRD) patterns were measured on a Panalytical X'Pert Pro X-ray Powder Diffractometer with a $\mathrm{Cu} \mathrm{Ka}$ source $(\lambda=1.54178 \AA)$, The intensities were recorded within the $2 \theta$ range from $10^{\circ}$ to $60^{\circ}$ with a voltage of $45 \mathrm{kV}$, and a current of $40 \mathrm{~mA}$. Scanning electron microscope image was measured with a JEOL JSM 6700F instrument. XANES and EXAFS were recorded at BL17C of National Synchrotron Radiation Research Center (NSRRC), Hsinchu, Taiwan. Gas chromatography-mass spectrometry (GC-MS) was performed on Agilent 6890-5975 GC-MS with Inert XL Selective Detector. The GC is equipped with a capillary HP-5MS column (Model No.: 19091S-433, $30.0 \mathrm{~m} \times 250 \mu \mathrm{m} \times 0.25 \mu \mathrm{m}$ ). The instrument is operated with an oven temperature of $50^{\circ} \mathrm{C}$, an inlet temperature of $280^{\circ} \mathrm{C}$, and a flow rate of $1.2 \mathrm{~mL} \mathrm{~min}^{-1}$ with helium carrier gas. A split/splitless injector is applied with a split ratio of $5: 1$ and a split flow of $5 \mathrm{~mL} \mathrm{~min}^{-1}$. The MS has a source temperature of $230^{\circ} \mathrm{C}$ and a quadrupole temperature of $150^{\circ} \mathrm{C}$. The SRI multiple gas analyzer \#5 GC is equipped with 3 S.S. columns including $18^{\prime \prime}$ Hayesep D, $3^{\prime}$ MS 5A and $6^{\prime}$ Hayesep D. The instrument is operated with an oven temperature of $50^{\circ} \mathrm{C}$, a temperature profile from 50 to $270^{\circ} \mathrm{C}$, and a flow rate of $40 \mathrm{~mL} \mathrm{~min}^{-1}$ at $15 \mathrm{psi}$ with argon carrier gas. X-ray photoelectron spectroscopy (XPS) was measured on a Kratos AXIS Ultra spectrometer (Kratos Analytical, Manchester, UK).

Catalyst preparation. Homogeneous bimetallic catalyst 1 was prepared by dis solving vanadium pentoxide $\left(\mathrm{V}_{2} \mathrm{O}_{5}\right)$ in $98 \% \mathrm{H}_{2} \mathrm{SO}_{4}$ with ultra-sound treatment for $6 \mathrm{~h}$. Homogeneous titanium (IV)-oxo and chromium (VI)-oxo catalysts were prepared by dissolved titanyl sulfate $\left(\mathrm{TiOSO}_{4}\right)$ and potassium chromate $\left(\mathrm{K}_{2} \mathrm{CrO}_{4}\right)$ in $98 \% \mathrm{H}_{2} \mathrm{SO}_{4}$, respectively. The heterogeneous variant $4\left(\mathrm{VOPO}_{4} \cdot 2 \mathrm{H}_{2} \mathrm{O}\right)$ was prepared based on previous literature ${ }^{37,40} . \mathrm{V}_{2} \mathrm{O}_{5}(4.8 \mathrm{~g}), \mathrm{H}_{3} \mathrm{PO}_{4}(85.5 \%, 26.6 \mathrm{~mL})$, and $\mathrm{H}_{2} \mathrm{O}(115.4 \mathrm{~mL})$ were refluxed at $110^{\circ} \mathrm{C}$ for $16 \mathrm{~h}$. After gently cooling down to room temperature, the yellow precipitate in the mixture was collected by filtration and washed several times with water and acetone. The resulting sample was dried in an oven at $100{ }^{\circ} \mathrm{C}$ for $3 \mathrm{~h}$. When 4 was investigated for its electrochemical response, $\mathbf{4}$ was loaded onto a FTO electrode via a dip-coating procedure. A dispersion of 4 was prepared at a concentration of $6 \mathrm{mg} \mathrm{mL}^{-1}$ in 2-propanol. The yellow dispersion was ultrasonicated for $30 \mathrm{~min}$ until the color of the dispersion became faded. Afterwards, sodium carboxymethyl cellulose (CMC) was added into the dispersion (weight ratio of $\mathrm{VOPO}_{4} \cdot 2 \mathrm{H}_{2} \mathrm{O}: \mathrm{CMC}=80$ : 5 ). The mixture was stirred at 600 revolution per minute (rpm) on the heating plate to remove excess 2 propanol and form a homogenous slurry, which was then dip-coated onto FTO at a loading amount of $1.9 \mathrm{mg} \mathrm{cm}^{-2}$ for 4 .

Electrochemical characterization. All electrochemical experiments were recorded using a Gamry Instruments Reference 600+ and Interface 1000 potentiostats. Unless mentioned specifically, a three-electrode setup was applied with a Pt wire pseudo-reference electrode and a $\mathrm{Pt}$ counter electrode. The Pt pseudo-reference electrode was calibrated to a $\mathrm{Hg}_{2} \mathrm{SO}_{4} / \mathrm{Hg}$ (saturated $\mathrm{K}_{2} \mathrm{SO}_{4}$ ) reference electrode ( $\mathrm{CH}$ Instrument, Inc.) via the measurement of open-circuit potentials. The relationship is $E\left(\mathrm{~V}\right.$ vs. $\left.\mathrm{Hg}_{2} \mathrm{SO}_{4} / \mathrm{Hg}\right)=E(\mathrm{~V}$ vs. $\mathrm{Pt})+0.755 \mathrm{~V}$. The gas environment of the electrochemical cell was controlled either $\mathrm{CH}_{4}$ (Airgas, 99.5\%) or $\mathrm{N}_{2}$ (Airgas, $99.999 \%)$, which were bubbled into the reactor at rates of $7.2\left(\mathrm{CH}_{4}\right)$ and $10\left(\mathrm{~N}_{2}\right)$ standard cubic centimeters per minute $(\mathrm{sccm})$ with the use of a mass flow controllers (Omega Engineering, Inc., FMA5510A). The data were reported after $i R$ compensation. Unless noted specifically, the electrolyte is $98 \% \mathrm{H}_{2} \mathrm{SO}_{4}$ with a certain vanadium concentration of 1 . 
Experiments of cyclic voltammetry were conducted in a single-chamber electrochemical cell with a 2-mm Pt working electrode (CH Instruments, Inc.). Bulk electrolysis with $5 \mathrm{~mL}$ homogeneous catalyst solution was typically conducted in a two-chamber electrochemical cell with a Nafion 117 membrane as the separator and a piece of commercial fluorine-doped tin-oxide (FTO) glass as the working electrode. Here, the FTO glass was encapsulated with Teflon tapes so that the exposed electrode is $1 \times 1 \mathrm{~cm}$ in dimension. The solution was pre-saturated with $\mathrm{CH}_{4}$ or $\mathrm{N}_{2}$ for 20 min before the commencement of electrolysis. The background signal contribution of FTO glass was subtracted for the recorded data. Liquid aliquots were taken before, during and after the electrolysis for product analysis. Gaseous samples were taken manually from the outgas of the reactor, diluted with pure $\mathrm{N}_{2}$ (1:5 ratio) for transportation purpose, and manually injected into the GC-MS. The injected permanent gas was not well separated by the column, but the MS spectra of the eluted gas peak $(t \sim 3.3 \mathrm{~min})$ was capable to quantify permanent gases with a detection limit of $\sim 10 \mathrm{ppm}$. Additional measurements of gas chromatography for the gaseous effluents was conducted by the SRI multiple gas analyzer \#5. The experiments at elevated pressure was conducted into a custom-designed setup utilizing a pressure vessel with two gas feedthrough and three electric feedthroughs (Parr Instrument, Series 4600, 1000 $\mathrm{mL}$ ). In this setup, the gas pressure was controlled between 1 and 11 bar and a constant gas flow of up to $28.7 \mathrm{sccm}$ was maintained during the electrolysis. The temperature of the electrolysis was maintained by an oil bath at a range between 25 and $55^{\circ} \mathrm{C}$. For experiments using substrates other than $\mathrm{CH}_{4}$, the same procedure is followed except the gas flow rate is set at $10 \mathrm{sccm}$ calibrated against $\mathrm{N}_{2}$. In the 240 -h electrolysis using natural gas mixture as the substrate, the electrolyte was refilled after each aliquot sampling in order to maintain a constant electrolyte volume. Experiment with $50 \%{ }^{13} \mathrm{C}$-enriched $\mathrm{CH}_{4}$ was conducted by feeding regular $\mathrm{CH}_{4}$ and ${ }^{13} \mathrm{CH}_{4}$ gases at equal flow rates controlled by two mass flow controller.

We found that typical reagent-grade $98 \% \mathrm{H}_{2} \mathrm{SO}_{4}$ possesses nonzero background activity toward $\mathrm{CH}_{4}$ at high electrochemical potential (Supplementary Fig. 16). We argue that such background activity is due to the trace metal impurity, possibly $\mathrm{V}$ as $\mathrm{H}_{2} \mathrm{SO}_{4}$ is industrially synthesized by a $\mathrm{V}_{2} \mathrm{O}_{5}$ catalyst in the contact process. The reagent-grade $98 \% \mathrm{H}_{2} \mathrm{SO}_{4}$ or oleum employed in most studies contains about 5 ppm of metal impurities (VWR BDH3074-3.8LP). When we employed high-purity $98 \% \mathrm{H}_{2} \mathrm{SO}_{4}$ (Sigma-Aldrich 339741) that only contained $0.3 \mathrm{ppm}$ of metal impurities as shown in the product certificate, the observed reactivity of neat $98 \%$ $\mathrm{H}_{2} \mathrm{SO}_{4}$ vanished (Supplementary Fig. 16).

When the heterogeneous variant $\mathbf{4}$ was investigated for its electrochemical response, a similar procedure was followed. However, owing to the difference of solution composition, the Pt pseudo-reference electrode has a different relationship with the $\mathrm{Hg}_{2} \mathrm{SO}_{4} / \mathrm{Hg}$ reference electrode: $E\left(\mathrm{~V}\right.$ vs. $\left.\mathrm{Hg}_{2} \mathrm{SO}_{4} / \mathrm{Hg}\right)=E(\mathrm{~V}$ vs. $\mathrm{Pt})+$ $0.268 \mathrm{~V}$.

Attempts of using chemical oxidants at ambient conditions. When $\mathrm{CH}_{4}(7.2$ sccm, 1 bar) was bubbled into a $98 \% \mathrm{H}_{2} \mathrm{SO}_{4}$ solution with $10 \mathrm{mM} 1$ and $10 \mathrm{mM}$ $\mathrm{K}_{2} \mathrm{~S}_{2} \mathrm{O}_{8}$ for $6 \mathrm{~h}$ at ambient conditions, the formation of methyl bisulfate $\left(\mathrm{CH}_{3} \mathrm{O}\right.$ $\mathrm{SO}_{3} \mathrm{H}$ ) as a possible product of $\mathrm{CH}_{4}$ oxidation was not observed (Supplementary Fig. 6f). Similar experiment was conducted with $10 \mathrm{mM} \mathrm{H}_{2} \mathrm{O}_{2}$ in lieu of $\mathrm{K}_{2} \mathrm{~S}_{2} \mathrm{O}_{8}$. The formation of methyl bisulfate $\left(\mathrm{CH}_{3} \mathrm{OSO}_{3} \mathrm{H}\right)$ as a possible product of $\mathrm{CH}_{4}$ oxidation was not observed (Supplementary Fig. 6f), either.

Quantification of liquid products. ${ }^{1} \mathrm{H}-\mathrm{NMR}$ was applied to quantify product accumulation in DMSO- $\mathrm{d}_{6}$ using acetic acid $\left(\mathrm{CH}_{3} \mathrm{COOH}\right)$ as the internal standard. Totally, $0.4 \mathrm{~mL}$ liquid aliquots from electrolysis were mixed with $0.1 \mathrm{~mL}$ DMSO- $\mathrm{d}_{6}$ prior to the measurements. Chemical shifts are reported on a parts-per-million (ppm) scale. Methyl bisulfate $\left(\mathrm{CH}_{3} \mathrm{OSO}_{3} \mathrm{H}\right)$ exhibits a singlet at $3.34 \mathrm{ppm}$ while the singlet from acetic acid $\left(\mathrm{CH}_{3} \mathrm{COOH}\right)$ peak resides at $1.96 \mathrm{ppm}$. A calibration curve was constructed by determining the relative ratio of integrated area between the NMR peaks of $\mathrm{CH}_{3} \mathrm{OSO}_{3} \mathrm{H}$ and $\mathrm{CH}_{3} \mathrm{COOH}$. Product quantification of $\mathrm{C}_{2} \mathrm{H}_{6}, \mathrm{C}_{3} \mathrm{H}_{8}$, and natural gas mixture follows the same protocol, except for the quantification of $\mathrm{CH}_{3} \mathrm{COOH}$ as a $\mathrm{C}_{2}$ product from $\mathrm{C}_{2} \mathrm{H}_{6}$. The quantification of $\mathrm{CH}_{3} \mathrm{COOH}$ as a $\mathrm{C}_{2}$ product was fulfilled by adding a known concentration of $\mathrm{CH}_{3} \mathrm{OSO}_{3} \mathrm{H}$ as an internal standard in a separate ${ }^{1} \mathrm{H}$-NMR measurement.

Calculation of FE. The F.E. of bulk electrolysis was calculated based on the following equation:

$$
\text { F.E. }=\frac{n F C_{\text {product }} V_{\text {solution }}}{\text { Overall charge }} \times 100 \%,
$$

Here, $F$ is the Faraday's constant, $C_{\text {product }}$ is the concentration of product after bulk electrolysis, $V_{\text {solution }}$ is the total electrolyte volume, and the overall charge is the total electric charges passed through the working electrode. The variable $n$ in the equation is the number of electrons required in order to generate one product molecule by electrochemistry. $n=2$ for the formation of methyl bisulfate $\left(\mathrm{CH}_{3} \mathrm{OSO}_{3} \mathrm{H}\right)$ from $\mathrm{CH}_{4} \cdot n=2$ and 6 for the formation of ethyl bisulfate $\left(\mathrm{C}_{2} \mathrm{H}_{5} \mathrm{OSO}_{3} \mathrm{H}\right)$ and acetic acid $\left(\mathrm{CH}_{3} \mathrm{COOH}\right)$ from $\mathrm{C}_{2} \mathrm{H}_{6}$, respectively. $n=2$ and 4 for the formation of isopropyl bisulfate $\left(i-\mathrm{C}_{3} \mathrm{H}_{7} \mathrm{OSO}_{3} \mathrm{H}\right)$ and acetone $\left(\mathrm{CH}_{3} \mathrm{COCH}_{3}\right)$ from $\mathrm{C}_{3} \mathrm{H}_{8}$, respectively.
Calculation of TOF and TON. In the following we provide the protocols that we calculate the TOFs and TONs for the reported data, based on the methods established in prior literature ${ }^{19,23}$.

The diffusion coefficient for $\mathbf{1}(D)$ was determined from the cyclic voltammgrams based on the Randles-Sevcik equation ${ }^{22}$ :

$$
j_{p}=0.4463 n F C_{\text {cat }}\left(\frac{n F v D}{R T}\right)^{\frac{1}{2}},
$$

Here $j_{\mathrm{p}}$ is the peak current density of quasi-reversible redox couple, $n$ is the number of electrons transferred in the redox event, $F$ is the Faraday's constant, $C_{c a t}$ is $\mathbf{1}$ 's concentration, $v$ is the scan rate, $R$ is the gas constant, and $T$ is the temperature of experiment. As derived from Supplementary Fig. $1 \mathrm{a}, \mathrm{b}, D=2.18 \times 10^{-7} \mathrm{~cm}^{2} \mathrm{~s}^{-1}$ for species $\mathbf{1}$ in the electrolyte.

The observed TOF of bulk electrolysis was determined based on the following equation $^{19,23}$ :

$$
\mathrm{TOF}=\left(\frac{j_{\text {product }}}{n F C_{\text {cat }}}\right)^{2} \frac{1}{D}
$$

Here, $j_{\text {product }}$ is the partial current density of product formation in bulk electrolysis, $n$ is the number of electrons required to generate one product molecule, $F$ is the Faraday's constant, $C_{\text {cat }}$ is the concentration of catalyst $1, D$ is the diffusion coefficent of catalyst $\left(2.18 \times 10^{-7} \mathrm{~cm}^{2} \mathrm{~s}^{-1}\right.$ for species 1 as determined above)

Similarly, the TON of bulk electrolysis was determined based on the following equation ${ }^{19,23}$,

$$
\mathrm{TON}=\frac{C_{\text {product }} V_{\text {solution }}}{A C_{\text {cat }}} \sqrt{\frac{\mathrm{TOF}}{D}} .
$$

Here, $C_{\text {product }}$ is the product concentration after bulk electrolysis, $V_{\text {solution }}$ is the total electrolyte volume, $A$ is the electrode area, $C_{\text {cat }}$ is the concentration of catalyst $\mathbf{1}, D$ is the diffusion coefficent of catalyst $\left(2.18 \times 10^{-7} \mathrm{~cm}^{2} \mathrm{~s}^{-1}\right.$ for species $\mathbf{1}$ as determined above), and TOF is the TOF calculated based on above protocol.

On the condition of a homogenous process with molecular catalyst $\mathbf{1}$, the diffusion coefficient extracted from the $\mathrm{V}(\mathrm{V}) / \mathrm{V}(\mathrm{IV})$ redox couple is a reasonable approximate of the real catalytic redox couple, the vanadium(V)-oxo dimer and its one-electron-deficient cation radical, because we are unable to characterize the cation radical due to its transient nature. Here, we offer a rough estimate of the relative uncertainty of such an approximation based on our proposed mechanism. The Stokes-Einstein relationship ${ }^{41}$ predicts that the diffusion coefficient $D$ of similar molecules follows: $D \sim \mathrm{MW}^{-1 / 3}$, in which $\mathrm{MW}$ is the molecular weight. As $\mathrm{MW}=538.16 \mathrm{~g} \mathrm{~mol}^{-1}$ for $\mathbf{1}$, the relative uncertainty of $D$ in our procedure is about $6 \%$ or $12 \%$, assuming the loss of one or even two of the sulfonic ligands, respectively. As the TOF $\sim D^{-123}$, at most about $10 \%$ relatively uncertainly will incur in our practice.

Computational methods. All calculations were performed with Turbomole ${ }^{42-52}$ using the M06 density functional ${ }^{53}$. The def2-SVP basis set was used for geometry optimizations and free energy corrections, and the def2-TZVP basis set was used for electronic energies ${ }^{54}$. Solvation was modeled with $\mathrm{COSMO}^{55}$ with the dielectric constant set to $101^{56}$. Images were rendered using Chemcraft ${ }^{57}$. The natural bond orbital (NBO) analysis was used for atomic charge calculations ${ }^{36}$.

Details of XAS experiments. XAS, including X-ray absorption near edge spectra (XANES) and extended X-ray absorption fine structure (EXAFS), at V K-edge were collected in total-fluorescence-yield mode at ambient conditions at BL17C of National Synchrotron Radiation Center (NSRRC), Hsinchu, Taiwan. Spectra were recorded in the energy range from -100 to $600 \mathrm{eV}$, relative to that of V K-edge absorption $(5465.0 \mathrm{eV})$. The XAS spectra were processed by subtracting the baseline of pre-edge and normalizing that of post-edge. EXAFS analysis was carried out using Fourier transform on $\mathrm{k}^{3}$-weighted EXAFS oscillations to assess the contribution of each bond pair to Fourier transform peak. The curve fitting of EXAFS spectra was conducted using the software, REX2000, with FEFF program.

The operando XAS experiments at V K-edge were conducted under the same procedure at TPS beamline 44A of NSRRC, Hsinchu, Taiwan. A three-electrode arrangement was used during the operando measurements. The electrolyte was saturated with 1-bar $\mathrm{CH}_{4}$, and the measurements were performed using an Autolab PGSTAT204 potentiostat (Metrohm Autolab) in a customized reactor.

Operando Raman characterization. A three-electrode setup in a home-made cell was adopted for Operando Raman spectroscopy and the electrochemical measurements. The measurements in a $\mathrm{CH}_{4}$-saturated electrolyte were recorded using a Raman microscopy (UniNano UNIDRON) and an Autolab PGSTAT204 potentiostat (Metrohm Autolab). A laser of $633 \mathrm{~nm}$ with a spot size of $\sim 1 \mu \mathrm{m}^{2}$ served as the excitation source, and the output power was $2.5 \mathrm{~mW}$. A $50 \times$ objective lens was employed for operando measurements during electrolysis, while all results were obtained under an exposure duration of $3 \mathrm{~s}$ with the accumulation number of 60 times. 


\section{Data availability}

The data that support the findings of this study are available from the corresponding author upon reasonable request. The source data underlying Figs. 2a, d-f, 3, and Supplementary Figs. 1a, b, 2c, 6c, 7, 9c, 11c, 11d, 13a, 15, 16, 17c, d are provided as Source Data file following the url: https://doi.org/10.6084/m9.figshare.12525524.

Received: 9 May 2020; Accepted: 1 July 2020;

Published online: 23 July 2020

\section{References}

1. McFarland, E. Unconventional chemistry for unconventional natural gas. Science 338, 340-342 (2012).

2. Schüth, F. Making more from methane. Science 363, 1282-1283 (2019).

3. Periana, R. A. et al. A mercury-catalyzed, high-yield system for the oxidation of methane to methanol. Science 259, 340-343 (1993).

4. Periana, R. A. et al. Platinum catalysts for the high-yield oxidation of methane to a methanol derivative. Science 280, 560-564 (1998).

5. O’Reilly, M. E., Kim, R. S., Oh, S. \& Surendranath, Y. Catalytic methane monofunctionalization by an electrogenerated high-valent Pd intermediate. ACS Cent. Sci. 3, 1174-1179 (2017).

6. Kim, R. S. \& Surendranath, Y. Electrochemical reoxidation enables continuous methane-to-methanol catalysis with aqueous Pt salts. ACS Cent. Sci. 5, 1179-1186 (2019).

7. Shan, J. J., Li, M. W., Allard, L. F., Lee, S. S. \& Flytzani-Stephanopoulos, M. Mild oxidation of methane to methanol or acetic acid on supported isolated rhodium catalysts. Nature 551, 605-608 (2017)

8. Mukhopadhyay, S. \& Bell, A. T. A high-yield approach to the sulfonation of methane to methanesulfonic acid initiated by $\mathrm{H}_{2} \mathrm{O}_{2}$ and a metal chloride. Angew. Chem. Int. Ed. 42, 2990-2993 (2003).

9. Basickes, N., Hogan, T. E. \& Sen, A. Radical-initiated functionalization of methane and ethane in fuming sulfuric acid. J. Am. Chem. Soc. 118, 13111-13112 (1996).

10. Nizova, G. V., SussFink, G. \& Shulpin, G. B. Catalytic oxidation of methane to methyl hydroperoxide and other oxygenates under mild conditions. Chem. Commun. 397-398 (1997).

11. Gunsalus, N. J. et al. Homogeneous functionalization of methane. Chem. Rev. 117, 8521-8573 (2017).

12. Shilov, A. E. \& Shul'pin, G. B. Activation of C-H bonds by metal complexes. Chem. Rev. 97, 2879-2932 (1997).

13. Meng, X. G. et al. Direct methane conversion under mild condition by thermo-, electro-, or photocatalysis. Chem 5, 2296-2325 (2019).

14. Zimmermann, T., Soorholtz, M., Bilke, M. \& Schüth, F. Selective methane oxidation catalyzed by platinum salts in oleum at turnover frequencies of large-scale industrial processes. J. Am. Chem. Soc. 138, 12395-12400 (2016).

15. Díaz-Urrutia, C. \& Ott, T. Activation of methane to $\mathrm{CH}_{3}{ }^{+}$: a selective industrial route to methanesulfonic acid. Science 363, 1326-1329 (2019).

16. Labinger, J. A. \& Bercaw, J. E. Understanding and exploiting C-H bond activation. Nature 417, 507-514 (2002).

17. Olah, G. A. Electrophilic methane conversion. Acc. Chem. Res. 20, 422-428 (1987).

18. Shilov, A. E. \& Shul'pin, G. B. Activation and Catalytic Reactions of Saturated Hydrocarbons in the Presence of Metal Complexes. (Springer, Dordrecht, 2000).

19. Savéant, J. M. Elements of Molecular and Biomolecular Electrochemistry. An Electrochemical Approach to Electron Transfer Chemistry. (Wiley, New Jersey, 2006).

20. Sauermann, N., Meyer, T. H., Qiu, Y. A. \& Ackermann, L. Electrocatalytic C$\mathrm{H}$ activation. ACS Catal. 8, 7086-7103 (2018).

21. Madic, C., Begun, G. M., Hahn, R. L., Launay, J. P. \& Thiessen, W. E. Dimerization of aquadioxovanadium $(\mathrm{V})$ ion in concentrated perchloric and sulfuric-acid media. Inorg. Chem. 23, 469-476 (1984).

22. Zanello, P. Inorganic Electrochemistry: Theory, Practice and Application. (Royal Society of Chemistry, London, 2003).

23. Costentin, C., Drouet, S., Robert, M. \& Saveant, J. M. Turnover numbers, turnover frequencies, and overpotential in molecular catalysis of electrochemical reactions. Cyclic voltammetry and preparative-scale electrolysis. J. Am. Chem. Soc. 134, 11235-11242 (2012).

24. Labinger, J. A. Selective alkane oxidation: hot and cold approaches to a hot problem. J. Mol. Catal. A 220, 27-35 (2004).

25. Konnick, M. M. et al. A mechanistic change results in 100 times faster $\mathrm{CH}$ functionalization for ethane versus methane by a homogeneous Pt catalyst. $J$. Am. Chem. Soc. 136, 10085-10094 (2014).

26. Natural Gas Safety Data Sheet by SoCalGas. https://www.socalgas.com/ documents/safety/safety-data-sheet-natural-gas.pdf.
27. Dinh, C. T., Li, Y. G. C. \& Sargent, E. H. Boosting the single-pass conversion for renewable chemical electrosynthesis. Joule 3, 13-15 (2019).

28. Ripatti, D. S., Veltman, T. R. \& Kanan, M. W. Carbon monoxide gas diffusion electrolysis that produces concentrated $\mathrm{C}_{2}$ products with high single-pass conversion. Joule 3, 240-256 (2019).

29. Zhu, J., Hii, K. K. \& Hellgardt, K. Toward a green generation of oxidant on demand: practical electrosynthesis of ammonium persulfate. ACS Sustain. Chem. Eng. 4, 2027-2036 (2016).

30. Radimer, K. J. \& McCarthy, M. J. Electrolytic Production of Sodium Persulfate. USA patent US 4,144,144 (1979).

31. Wong, J., Lytle, F. W., Messmer, R. P. \& Maylotte, D. H. K-edge absorptionspectra of selected vanadium compounds. Phys. Rev. B 30, 5596-5610 (1984).

32. Bunker, G. Introduction to XAFS: A Practical Guide to X-Ray Absorption Fine Structure Spectroscopy. (Cambridge University Press, Cambridge, 2010).

33. Yamada, S., Katayama, C., Tanaka, J. \& Tanaka, M. Molecular structure of (uoxo)bis[oxobis(8-quinolinolato)vanadium(V)]. Inorg. Chem. 23, 253-255 (1984).

34. Bai, L. C., Hsu, C. S., Alexander, D. T. L., Chen, H. M. \& Hu, X. L. A cobaltiron double-atom catalyst for the oxygen evolution reaction. J. Am. Chem. Soc. 141, 14190-14199 (2019).

35. Huang, X. Y. \& Groves, J. T. Beyond ferryl-mediated hydroxylation: 40 years of the rebound mechanism and $\mathrm{C}-\mathrm{H}$ activation. J. Biol. Inorg. Chem. 22, 185-207 (2017).

36. Reed, A. E., Weinstock, R. B. \& Weinhold, F. Natural population analysis. J. Chem. Phys. 83, 735-746 (1985).

37. Wu, C. Z. et al. Two-dimensional vanadyl phosphate ultrathin nanosheets for high energy density and flexible pseudocapacitors. Nat. Commun. 4, 2431 (2013).

38. Michalkiewicz, B., Ziebro, J. \& Tomaszewska, M. Preliminary investigation of low pressure membrane distillation of methyl bisulphate from its solutions in fuming sulphuric acid combined with hydrolysis to methanol. J. Membr. Sci. 286, 223-227 (2006).

39. Higgins, D., Hahn, C., Xiang, C. X., Jaramillo, T. F. \& Weber, A. Z. Gasdiffusion electrodes for carbon dioxide reduction: a new paradigm. ACS Energy Lett. 4, 317-324 (2019).

40. Yamamoto, N., Hiyoshi, N. \& Okuhara, T. Thin-layered sheets of $\mathrm{VOHPO}_{4} \cdot 0.5 \mathrm{H}_{2} \mathrm{O}$ prepared from $\mathrm{VOPO}_{4} \cdot 2 \mathrm{H}_{2} \mathrm{O}$ by intercalation-exfoliationreduction in alcohol. Chem. Mater. 14, 3882-3888 (2002).

41. Young, M. E., Carroad, P. A. \& Bell, R. L. Estimation of diffusion-coefficients of proteins. Biotechnol. Bioeng. 22, 947-955 (1980).

42. Ahlrichs, R., Bar, M., Haser, M., Horn, H. \& Kolmel, C. Electronic-structure calculations on workstation computers-the program system turbomole. Chem. Phys. Lett. 162, 165-169 (1989).

43. Haser, M. \& Ahlrichs, R. Improvements on the direct SCF method. J. Comput. Chem. 10, 104-111 (1989).

44. Treutler, O. \& Ahlrichs, R. Efficient molecular numerical-integration schemes. J. Chem. Phys. 102, 346-354 (1995).

45. Eichkorn, K., Weigend, F., Treutler, O. \& Ahlrichs, R. Auxiliary basis sets for main row atoms and transition metals and their use to approximate Coulomb potentials. Theor. Chem. Acc. 97, 119-124 (1997).

46. Eichkorn, K., Treutler, O., Ohm, H., Haser, M. \& Ahlrichs, R. Auxiliary basissets to approximate Coulomb potentials. Chem. Phys. Lett. 242, 652-660 (1995).

47. Weigend, F. Accurate Coulomb-fitting basis sets for $\mathrm{H}$ to Rn. Phys. Chem Chem. Phys. 8, 1057-1065 (2006).

48. Sierka, M., Hogekamp, A. \& Ahlrichs, R. Fast evaluation of the Coulomb potential for electron densities using multipole accelerated resolution of identity approximation. J. Chem. Phys. 118, 9136-9148 (2003).

49. Deglmann, P., May, K., Furche, F. \& Ahlrichs, R. Nuclear second analytical derivative calculations using auxiliary basis set expansions. Chem. Phys. Lett. 384, 103-107 (2004).

50. Arnim, M. V. \& Ahlrichs, R. Parallelization of density functional and RICoulomb approximation in turbomole. J. Comp. Chem. 19, 1746-1757 (1998).

51. von Arnim, M. \& Ahlrichs, R. Geometry optimization in generalized natural internal coordinates. J. Chem. Phys. 111, 9183-9190 (1999).

52. Ahlrichs, R. Efficient evaluation of three-center two-electron integrals over Gaussian functions. Phys. Chem. Chem. Phys. 6, 5119-5121 (2004).

53. Zhao, Y. \& Truhlar, D. G. The M06 suite of density functionals for main group thermochemistry, thermochemical kinetics, noncovalent interactions, excited states, and transition elements: two new functionals and systematic testing of four M06-class functionals and 12 other functionals. Theor. Chem. Acc. 120, 215-241 (2008).

54. Weigend, F. \& Ahlrichs, R. Balanced basis sets of split valence, triple zeta valence and quadruple zeta valence quality for $\mathrm{H}$ to $\mathrm{Rn}$ : Design and assessment of accuracy. Phys. Chem. Chem. Phys. 7, 3297-3305 (2005).

55. Klamt, A. \& Schuurmann, G. Cosmo-a new approach to dielectric screening in solvents with explicit expressions for the screening energy and its gradient. J. Chem. Soc. Perkin Trans. 2, 799-805 (1993).

56. Gillespie, R. J. \& Cole, R. H. The dielectric constant of sulphuric acid. Trans. Faraday Soc. 52, 1325-1331 (1956). 
57. Chemcraft-graphical software for visualization of quantum chemistry computations. https://www.chemcraftprog.com.

\section{Acknowledgements}

J.A.I. is supported by a Eugene V. Cota-Robles fellowship. D.Y. thanks the visiting graduate student fellowship from the China Scholarship Council. H.M.C. acknowledges the Ministry of Science and Technology, Taiwan (Contract no. MOST 107-2628-M-002015-RSP). A.N.A. acknowledges the NSF Career Award (CHE-1351968), and the XSEDE and the UCLA-IDRE cluster Hoffman2 for computational resources. C.L. acknowledges the NSF Award (CHE-1955836), startup fund from the University of California, Los Angeles and the financial support of the Jeffery and Helo Zink Endowed Professional Development Term Chair. We thank Lina Gao and Xueqian Kong for the measurement of ${ }^{51} \mathrm{~V}$ NMR spectroscopy, Weilai Yu and the Molecular Materials Research Center of the Beckman Institute of the California Institute of Technology for the measurement of XPS, Paula Diaconescu, Hosea Nelson, and Alexander Spokoyny for helpful discussions.

\section{Author contributions}

C.L. supervised the project. J.D. conducted the majority of electrolysis experiments and assisted the initial experiment design. S.C.L. conducted the XAS and operando Raman experiments and analyzed the data under supervision of H.M.C. J.A.I. participated the initial experiment design and first reported the catalytic activities. J.A.I., D.X., G.C., and D.Y. participated in the catalyst characterization. J.F. performed the DFT calculations under the supervision of A.N.A. C.L., J.D., and S.C.L. analyzed the data and wrote the initial draft of paper. All the authors discussed the results and assisted during the paper preparation.

\section{Competing interests}

A provisional patent has been filed under the names of C.L., J.D., and J.A.I. (U.S. 62/ $890,271)$. Remaining authors declare no competing interests.

\section{Additional information}

Supplementary information is available for this paper at https://doi.org/10.1038/s41467020-17494-w.

Correspondence and requests for materials should be addressed to H.M.C., A.N.A. or C.L.

Peer review information Nature Communications thanks Timo Ott and the other, anonymous, reviewer(s) for their contribution to the peer review of this work.

Reprints and permission information is available at http://www.nature.com/reprints

Publisher's note Springer Nature remains neutral with regard to jurisdictional claims in published maps and institutional affiliations.

(c) (i) Open Access This article is licensed under a Creative Commons Attribution 4.0 International License, which permits use, sharing, adaptation, distribution and reproduction in any medium or format, as long as you give appropriate credit to the original author(s) and the source, provide a link to the Creative Commons license, and indicate if changes were made. The images or other third party material in this article are included in the article's Creative Commons license, unless indicated otherwise in a credit line to the material. If material is not included in the article's Creative Commons license and your intended use is not permitted by statutory regulation or exceeds the permitted use, you will need to obtain permission directly from the copyright holder. To view a copy of this license, visit http://creativecommons.org/ licenses/by/4.0/.

(C) The Author(s) 2020 